\title{
Anesthesia Considerations in Emergency C-Section and Perioperative Neonatal Resuscitation: A Case Report and Review of Literature
}

\author{
Pratap Nadavaluru*, Stephen Hannaford, Molly Amin, Hee Jung Park, Ming Xiong \\ Department of Anesthesiology \& Perioperative Medicine, Rutgers New Jersey Medical School, Newark, USA \\ Email: *npreddy59@gmail.com
}

How to cite this paper: Nadavaluru, P., Hannaford, S., Amin, M., Park, H.J. and Xiong, M. (2018) Anesthesia Considerations in Emergency C-Section and Perioperative Neonatal Resuscitation: A Case Report and Review of Literature. Open Journal of Obstetrics and Gynecology, 8, 803-811.

https://doi.org/10.4236/ojog.2018.89083

Received: April 16, 2018

Accepted: August 5, 2018

Published: August 8, 2018

Copyright $\odot 2018$ by authors and Scientific Research Publishing Inc. This work is licensed under the Creative Commons Attribution International License (CC BY 4.0).

http://creativecommons.org/licenses/by/4.0/

\begin{abstract}
Emergency C-sections are performed for various reasons. This is a case report of emergency C-section performed due to fetal distress. This is a classic case report which emphasizes the importance of managing emergency $\mathrm{C}$-sections according to international standards and acknowledges co-operation of obstetrician and anesthesiologist. We reviewed literature about emergency $\mathrm{C}$-sections and discussed sensitive time intervals, types of anesthesia and neonatal resuscitation.
\end{abstract}

\section{Keywords}

Anesthesia for C-Section, Emergency C-Section, Perioperative Neonatal Resuscitation

\section{Introduction}

Emergency C-sections are very challenging for both anesthesiologists and obstetricians. They are associated with significant morbidity and mortality for both mother and newborn. This is a case of severe preeclampsia with a category 2 fetal heart rate tracing, which required emergency $\mathrm{C}$-section. In this case report and literature review, we described choice of anesthesia, decision to delivery interval (DDI) and neonatal resuscitation.

\section{Case}

A 25 y/o F G3P1101, estimated gestational age (EGA): 36w5d, with previous history of severe preeclampsia and preterm labor, $\mathrm{s} / \mathrm{p}$ cervical cerclage presented 
to clinic with nausea, increased leg swelling, elevated blood pressure (BP) 160/88 in clinic, which did not resolve with labetalol 10mg IV and then resolved with IV hydralazine $5 \mathrm{mg}$ IV to $145 / 78$. Cerclage was removed anticipating delivery without complications. Cervix 1/50/-3 after cerclage removal. Fetal heart Tracing category 2 with baseline $140 \mathrm{bpm}$, minimal variability, accelerations, recurrent deceleration that are a combination of late and variable decelerations as shown in Figure 1. Abnormal labs: Protein $>500$ on UA. Normal complete blood count (CBC), basic metabolic panel, Liver function tests and PT/PTT. Normal Ultra sonogram. Patient admitted to severe pre-eclampsia unit started on magnesium for seizure prophylaxis and IV Hydralazine for elevated BP. Plan made to start induction of labor, continue to monitor BPs and fetal heart Tracing with intrauterine resuscitation and if unchanged will go for cesarean delivery. Penicillin prophylaxis for GBS unknown.

\subsection{Labor and Delivery Unit Course}

The patient was admitted for induction of labor with vaginal insertion of Cytotec, and several hours later was noticed to have decelerations to $80 \mathrm{bpm}$ on fetal heart monitoring. These resolved after administration of $\mathrm{O}_{2}$ and left sided-positioning. However, subsequent episodes of decelerations were noted to $90 \mathrm{bpm}$ and 70 bpm as shown in Figure 2. The decision was made to take the patient for $\mathrm{C}$-section due to fetal bradycardia and category 2 fetal heart tracing.

\subsection{Intraoperative Course}

C-section was performed under General anesthesia. IV Induction with Propofol $160 \mathrm{mg}$ and Succinylcholine $100 \mathrm{mg}$ and easy intubation with MAC 3 blade and ETT 7.0. Sevoflurane was used as maintenance agent for GA. Neonatology team was consulted and was present during C-section prior to delivery of Newborn. Newborn delivered with no spontaneous cry, cyanotic and no HR or respirations.

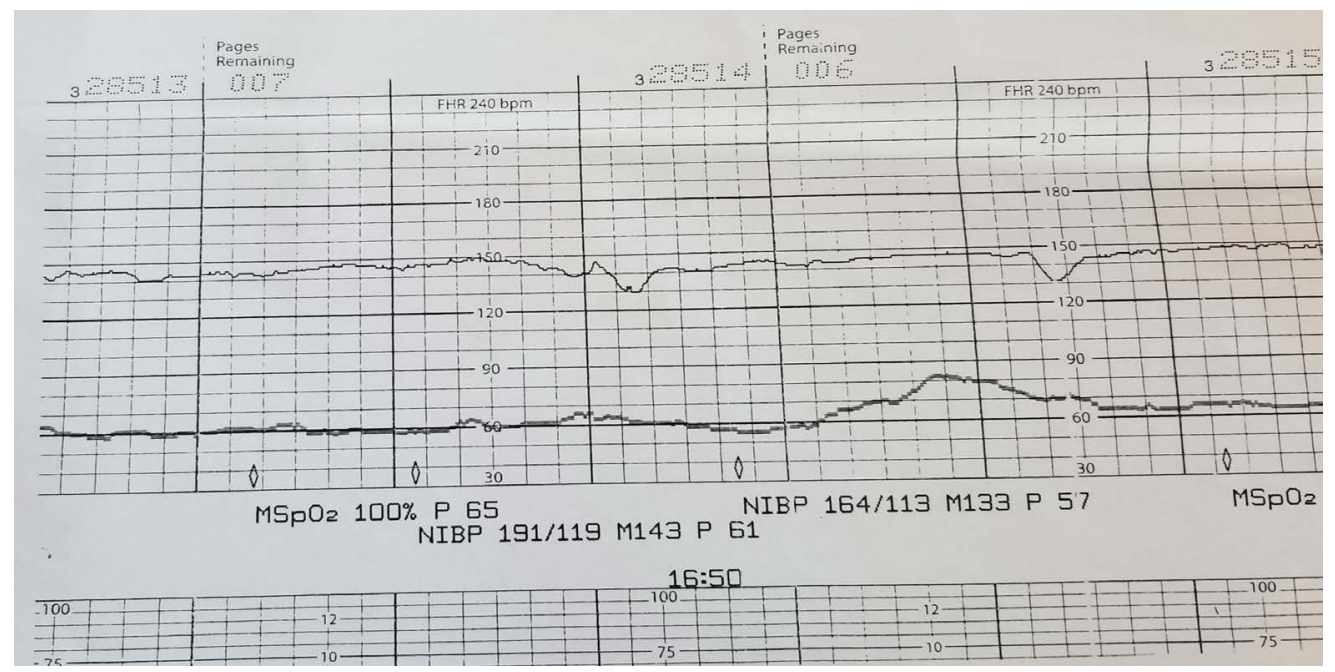

Figure 1. Fetal heart Tracing category 2, Baseline FHR140 bpm with minimal variability, accelerations, recurrent deceleration that are a combination of late and variable decelerations. 


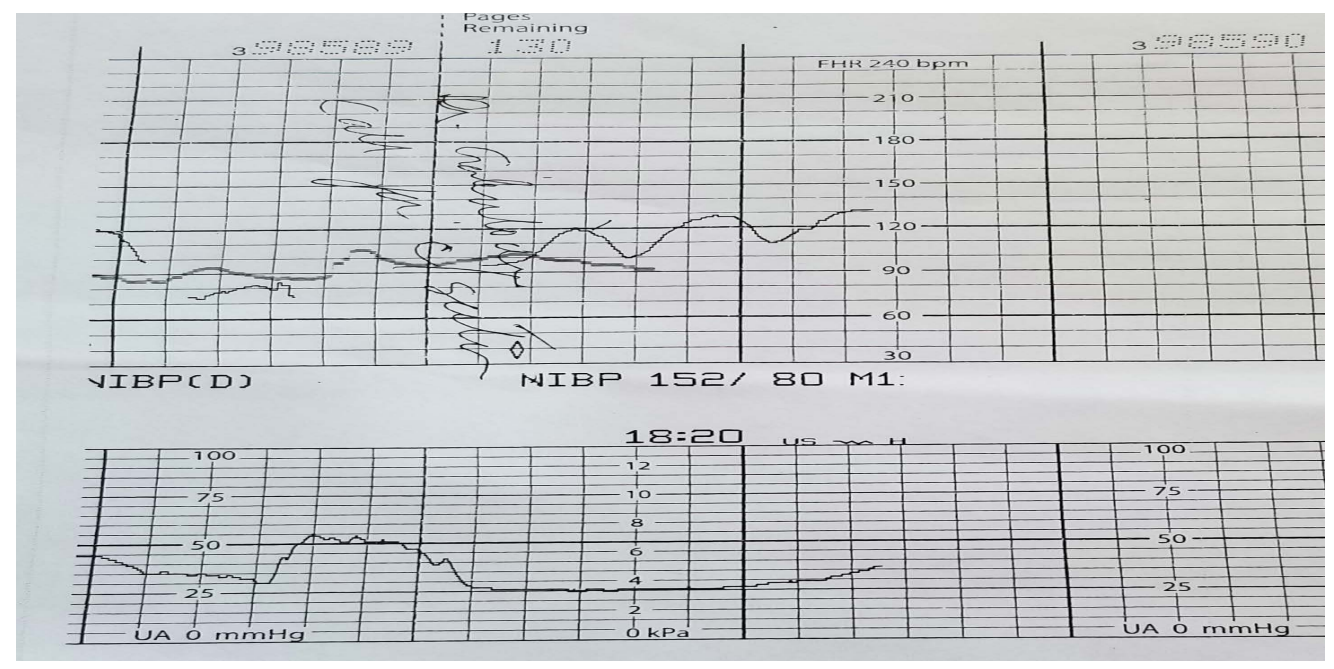

Figure 2. Category 2 Fetal heart rate tracing with temporary decelerations to $80 \mathrm{bpm}$ with subsequent episodes of decelerations to $90 \mathrm{bpm}$ and $70 \mathrm{bpm}$ and bradycardia.

APGAR scores were 0 (1 $\mathrm{min}), 0$ (2 $\mathrm{min}), 0$ (3 $\mathrm{min}), 2$ (10 $\mathrm{min})$, and 3 (20 $\mathrm{min})$. The neonatologist began non-invasive ventilation and CPR. Ultimately, intubation was performed, and two doses of epinephrine $(0.3 \mathrm{ml}$ and $0.6 \mathrm{ml})$ were administered. At 11 minutes of life HR noted to be $95 \mathrm{bpm}$. The baby was transferred to NICU with $\mathrm{HR}$ of $120 \mathrm{bpm}, \mathrm{SPO}_{2} 90$ 's on $100 \% \mathrm{O}_{2}$. Decision to delivery interval was $12 \mathrm{~min}$ and in room to delivery interval was $7 \mathrm{~min}$.

\subsection{Post Delivery Neonatal Course}

Post-delivery baby was admitted to NICU and was started on hypothermia protocol due to clinical encephalopathy and severe acidosis on cord gas with $\mathrm{pH}$ of 6.5. She received IV Ampicillin and Cefepime for three days. Neurology was consulted. VEEG done, which did not reveal any epileptiform activity. Baby was eventually weaned to RA. She stayed a total of 2 weeks in the NICU and intermediate care nursery. Head US revealed an echogenic periventricular area in the left parietal lobe which may represent hypoxic ischemic encephalopathy (HIE). MRI brain with spectroscopy showed T2 hyperintensity in the left parietal periventricular white mater (likely secondary to ischemic insult) and a focus of hypointensity along the left caudothalamic groove (likely sequela of prior hemorrhage).

Baby is having regular follow up clinic visits. Despite her difficult birth baby is developing normally. No deficits noted in the neurological exam. She is feeding, voiding and stooling normally.

\section{Discussion}

Emergency C-section is defined as C-section required because of immediate threat to life of woman or fetus. Urgent is defined as C-section required because of maternal or fetal compromise which is not immediately life-threatening. Scheduled is defined as needing early delivery but no maternal or fetal compro- 
mise. Elective is defined as C-section performed at a time to suit the woman and maternity team [1]. DDI of 30 minutes is widely used as an audit standard for emergency C-section. DDI can be optimized with a properly organized, well trained, and cooperative multidisciplinary team. In one institution, which implemented a protocol for extremely urgent $\mathrm{C}$-sections, managed to achieve a mean DDI of 7 minutes with $100 \%$ deliveries made within 17 minutes [2]. There is a lack of firm evidence supporting better outcomes with DDI $\leq 30$ minutes, when compared with one that is greater than 30 minutes [3]. For Grade 1 cases, the National Institute for Health and Clinical Excellence (NICE) clinical guidelines advise pursuing the shortest-possible DDI in order to maximize maternal and fetal outcomes [4] [5]. For grade 2 cases, studies have shown poorer neonatal outcomes when DDI is greater than 75 min.

As it can be administered rapidly, GA is almost always recommended in emergency situations with the hope of improving neonatal survival without hypoxic-ischemic brain injury [6]. However, careful assessment of every patient-most importantly, of the patient's airway must be carried out before choosing a method of anesthesia. A predicted difficult airway as in pregnant patients is sometimes considered a contra-indication to rapid sequence induction of general anesthesia, even in an urgent case such as a category-1 caesarean section for fetal distress. A. J. Krom et al. have used decision analysis to quantify the time taken to establish anesthesia, and probability of failure, of three possible anesthetic methods, based on a systematic review of the literature. They considered rapid sequence induction of general anesthesia with video laryngoscopy, awake fiberoptic intubation and rapid spinal anesthesia. Their results show a shorter mean (95\% CI) time to induction of 100 (87 - 114) s using rapid sequence induction compared with 9 (7 - 11) min for awake fiberoptic intubation $(\mathrm{p}<0.0001)$ and $6.3(5.4-7.2) \mathrm{min}$ for spinal anesthesia $(\mathrm{p}<0.0001)$. They calculated the risk of ultimate failed airway control after rapid sequence induction to be $21(0-53)$ per 100,000 cases, and postulate that some mothers may accept such a risk in order to reduce potential fetal harm from an extended time interval until delivery. Although rapid sequence induction may not be the anesthetic technique of choice for all cases in the circumstance of a category-1 caesarean section for fetal distress with a predicted difficult airway, they suggest that it is an acceptable option [7].

In the UK, a case series of 25 patients has described the use of spinal anesthesia in grade $1 \mathrm{C}$-sections. It is reported that anesthesia can be administered safely in suitable parturient in 6 - 8 min with "rapid sequence spinal anesthesia", which consists of a "no touch technique" of donning gloves, the omission of spinal opioids with an increase of the dose of hyperbaric Bupivacaine $0.5 \%$ (up to 3 $\mathrm{ml}$ ), and a limitation in the number of attempts [8]. Therefore, rapid sequence spinal anesthesia is a reasonable alternative to general anesthesia for urgent cesarean section cases [9].

Further literature review revealed, we should consider the need for an emer- 
gency hysterotomy (cesarean delivery) protocol as soon as 4 - 5 minutes after cardiac arrest in a pregnant woman to improve the survival rate of neonate [10] [11] [12] [13].

According to the National Institute of Child Health and Human Development (NICHD) workshop report, a category I FHR pattern will have moderate variability. A category II pattern will have minimal variability, or absent variability accompanied by recurrent decelerations or marked variability. A category III pattern will have absent variability with recurrent late decelerations, recurrent variable decelerations or bradycardia [14].

Neonatal resuscitation is summarized in Algorithm 1 and Algorithm 2 and Table 1 [15] [16] [17] [18]. If adequate chest compressions have failed to increase the $\mathrm{HR}>60 \mathrm{bpm}$, then it is reasonable to use adrenaline despite the lack of human neonatal data. If Adrenaline is indicated, a dose of $0.01-0.03 \mathrm{mg} / \mathrm{kg}$ should be administered intravenously. If there is no IV access, $0.05-0.1 \mathrm{mg} / \mathrm{kg}$ of Adrenaline can be administered via the tracheal route (Algorithm 1, Algorithm 2 and Table 1) [19].

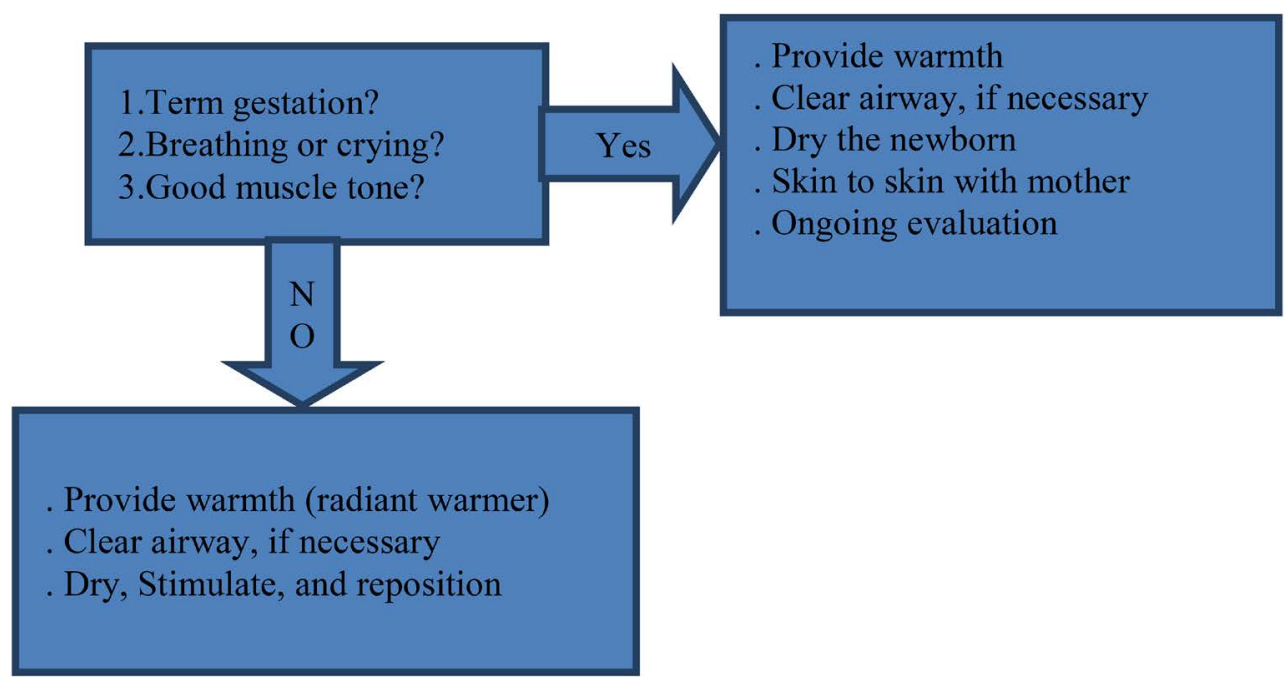

Algorithm 1. Initial newborn evaluation.
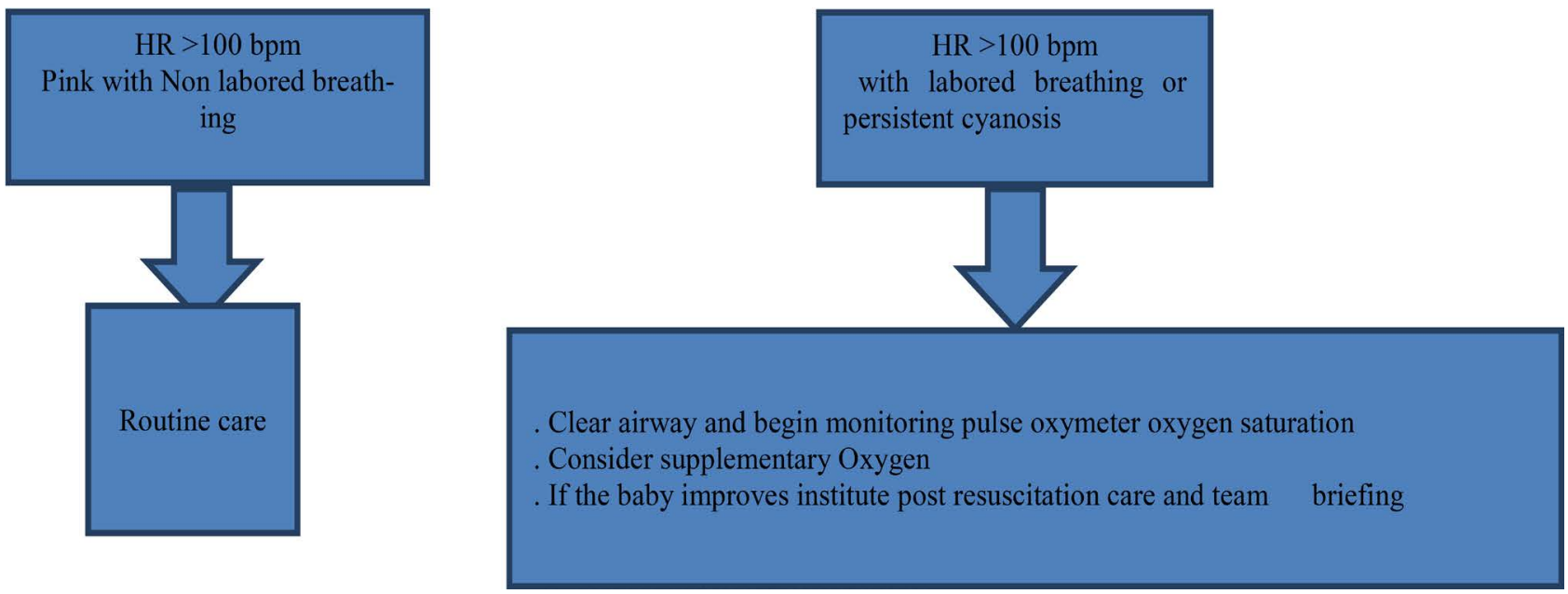


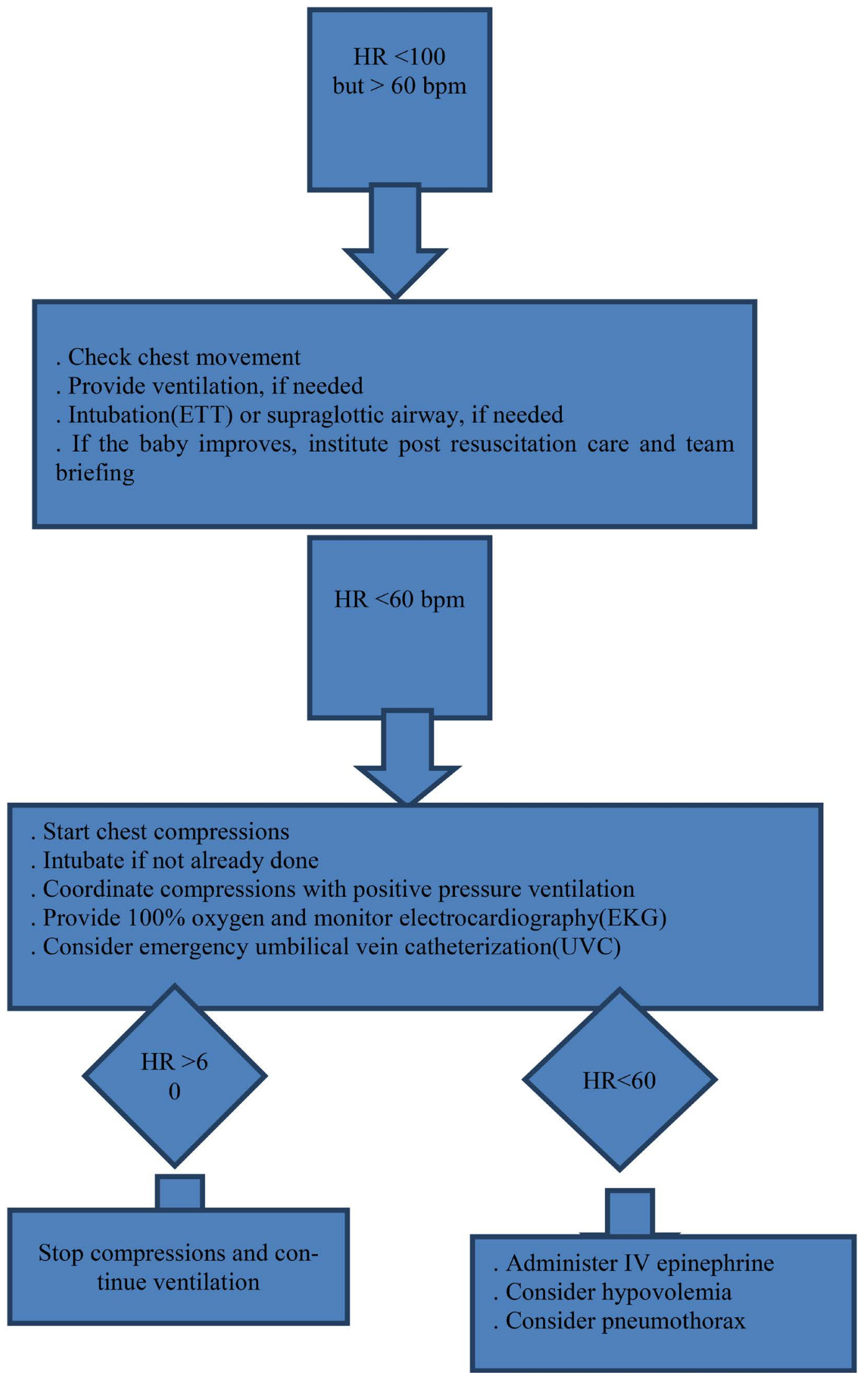

Algorithm 2. Secondary evaluation. 
Table 1. Neonatal resuscitation summarization.

\begin{tabular}{|c|c|}
\hline \multirow[t]{5}{*}{ Drug Therapy } & $\begin{array}{l}\text { Epinephrine } 0.01-0.03 \mathrm{mg} / \mathrm{kg} \text { IV } / \mathrm{IO} \text {; repeat every } 3-5 \text { minutes if heart rate is less than } 60 \mathrm{bpm} \text {. Epinephrine } \\
0.05-0.1 \mathrm{mg} / \mathrm{kg} \text { ETT (not preferred route). }\end{array}$ \\
\hline & Crystalloid $10 \mathrm{~mL} / \mathrm{kg}$ IV/IO \\
\hline & Sodium bicarbonate (4.2\%) $1-2 \mathrm{mEq} / \mathrm{kg}$ IV/IO only for prolonged resuscitation and only if effective ventilation \\
\hline & Dextrose (10\%) $0.2 \mathrm{~g} / \mathrm{kg}$ then $5 \mathrm{~mL} / \mathrm{kg} / \mathrm{hr}$ IV/IO if blood glucose level is less than $40 \mathrm{mg} / \mathrm{dL}$ \\
\hline & Naloxone is not recommended \\
\hline \multirow[t]{7}{*}{ Compressions } & Check pulse at brachial or femoral artery. \\
\hline & Compression landmarks: Lower third of sternum between the nipples Method: Thumb-encircling \\
\hline & Depth: Approximately one-third anteroposterior chest diameter \\
\hline & Allow complete chest recoil after each compression \\
\hline & Compression rate: 100 - 120 per minute \\
\hline & Compression-to-ventilation ratio of $3: 1$ \\
\hline & Coordinate compressions with ventilation Minimize interruptions in compressions to less than 10 seconds \\
\hline \multirow[t]{3}{*}{ Airway } & Preterm newborns ( $<35$ weeks) should receive low oxygen $\left(\mathrm{FiO}_{2} 21 \%\right.$ - 30\%). \\
\hline & Suction after birth is only for babies with obvious obstruction or who require positive pressure ventilation. \\
\hline & Suctioning during delivery has been shown to have no value. \\
\hline \multirow[t]{3}{*}{ Meconium } & $\begin{array}{l}\text { If meconium is present and the newborn is vigorous with good respiratory effort and muscle tone, he or she may } \\
\text { stay with the mother, and bulb suctioning can be considered. }\end{array}$ \\
\hline & $\begin{array}{l}\text { If the infant is born through meconium-stained amniotic fluid and presents with poor muscle tone and } \\
\text { inadequate breathing efforts, move him or her to a radiant warmer and follow typical initial evaluation steps. }\end{array}$ \\
\hline & $\begin{array}{l}\text { If meconium is present, routine intubation for tracheal suction is not recommended. If meconium is present and } \\
\text { the infant is nonvigorous, current literature does not support routine intubation. }\end{array}$ \\
\hline \multirow[t]{3}{*}{ Ventilations } & Rate of 40 - 60 breaths per minute \\
\hline & Watch for visible chest rise. \\
\hline & Administer positive end-expiratory pressure (PEEP), if available. \\
\hline \multirow[t]{3}{*}{ Consider Intubation } & Ineffective or prolonged bag-mask ventilation \\
\hline & Cardiopulmonary resuscitation $(\mathrm{CPR})$ is being performed \\
\hline & Special circumstances such as congenital diaphragmatic hernia \\
\hline $\begin{array}{l}\text { Target Preductal } \mathrm{SpO}_{2} \\
\text { At Birth }\end{array}$ & $\begin{array}{l}1 \text { minute: } 60 \% \text { - } 65 \% 2 \text { minutes: } 65 \% \text { - } 70 \% 3 \text { minutes: } 70 \% \text { - } 75 \% 4 \text { minutes: } 75 \% \text { - } 80 \% 5 \text { minutes: } 80 \% \text { - } 85 \% 10 \\
\text { minutes: } 85 \%-95 \%\end{array}$ \\
\hline
\end{tabular}

\section{Acknowledgements}

The author states that the report describes the care of one or more patients. The patient consented to publication of the report. This is described in the report. No external funding and no competing interests declared.

\section{Conflicts of Interest}

The authors declare no conflicts of interest regarding the publication of this paper. 


\section{References}

[1] Yeoh, S.B. and Jin, Li, S. (2013) Anesthesia for Emergency Caesarian Section. Current Anaesthesia and Critical Care, 3, 157-161.

[2] Lucas, D.N., Yentis, S.M., Kinsella, S.M., et al. (2000) Urgency of Caesarean Section: A New Classification. Journal of the Royal Society of Medicine, 93, 346-350. https://doi.org/10.1177/014107680009300703

[3] Lim, Y., Shah, M.K. and Tan, H.M. (2005) Evaluation of Surgical and Anaesthesia Response Times for Crash Caesarean Sections-An Audit of a Singapore Hospital. Annals Academy of Medicine Singapore, 34, 606-610.

[4] Lucas, D.N. (2010) The 30-Minute Decision to Delivery Time Is Unrealistic in Morbidly Obese Women. International Journal of Obstetric Anesthesia, 19, 431-435. https://doi.org/10.1016/j.ijoa.2010.07.020

[5] Caesarean Section [Internet]. Manchester (UK): National Institute for Health and Clinical Excellence; November 2011. http://nice.org.uk/guidance/cg132

[6] Thomas, J., Paranjothy, S. and James, D. (2004) National Cross Sectional Survey to Determine Whether the Decision to Delivery Interval Is Critical in Emergency Caesarean Section. BMJ, 328, 665. https://doi.org/10.1136/bmj.38031.775845.7C

[7] Krom, A.J., Cohen, Y., Miller, J.P., Ezri, T., Halpern, S.H. and Ginosar, Y. (2017) Choice of Anesthesia for Category-1 Caesarean Section in Women with Anticipated Difficult Tracheal Intubation: The Use of Decision Analysis. Anaesthesia, 72, 156-171. https://doi.org/10.1111/anae.13729

[8] Levy, D.M. (2006) Emergency Caesarean Section: Best Practice. Anaesthesia, 61, 786-791. https://doi.org/10.1111/j.1365-2044.2006.04711.x

[9] Sumikura, H. (2016) Anesthetic Management of Urgent Cesarean Section. J-STAGE, 4, 1-5.

[10] Morris, S. and Stacey, M. (2003) Resuscitation in Pregnancy. BMJ, 327, 1277-1279. https://doi.org/10.1136/bmj.327.7426.1277

[11] Katz, V.L., Dotters, D.J. and Droegemueller, W. (1986) Perimortem Cesarean Delivery. Obstetrics \& Gynecology, 68, 571-576.

[12] American Heart Association in Collaboration with International Liaison Committee on Resuscitation (2000) Guidelines 2000 for Cardiopulmonary Resuscitation and Emergency Cardiovascular Care: International Consensus on Science, Part 8: Advanced Challenges in Resuscitation: Section 3: Advanced Challenges in ECC. Circulation, 102, I229-I252.

[13] Cummins, R.O., Hazinski, M.F. and Zelop, C.M. (2003) Cardiac Arrest Associated with Pregnancy. In: Cummins, R., Hazinski, M. and Field, J., Eds., ACLS-The Reference Textbook, American Heart Association, Dallas, 143-158.

[14] Macones, G.A., Hankins, G.D., Spong, C.Y., Hauth, J. and Moore, T. (2008) The 2008 National Institute of Child Health and Human Development Workshop Report on Electronic Fetal Monitoring: Update on Definitions, Interpretation, and Research Guidelines. Obstetrics \& Gynecology, 112, 661-666. https://doi.org/10.1097/AOG.0b013e3181841395

[15] Wyckoff, M.H., et al. (2015) Part 13: Neonatal Resuscitation: 2015 American Heart Association Guidelines Update for Cardiopulmonary Resuscitation and Emergency Cardiovascular Care. Circulation, 132, S543-S560.

https://doi.org/10.1161/CIR.0000000000000267

[16] American Heart Association. Newborn (2015) Handbook of Emergency Cardiovascular Care for Healthcare Providers. November 2015, 73-76. 
[17] Kattwinkel, J., et al. (2010) Part 15: Neonatal Resuscitation: 2010 American Heart Association Guidelines for Cardiopulmonary Resuscitation and Emergency Cardiovascular Care. Circulation, 122, S909-S919. https://doi.org/10.1161/CIRCULATIONAHA.110.971119

[18] Atkins, D.L., et al. (2015) Part 11: Pediatric Basic Life Support and Cardiopulmonary Resuscitation Quality: 2015 American Heart Association Guidelines Update for Cardiopulmonary Resuscitation and Emergency Cardiovascular Care. Circulation, 132, S519-S525. https://doi.org/10.1161/CIR.0000000000000265

[19] Wyllie, J., Perlman, J.M., Kattwinkel, J., Atkins, D.L., Chameides, L., Goldsmith, J.P., Guinsburg, R., Hazinski, M.F., Morley, C., Richmond, S., Simon, W.M., Singhal, N., Szyld, E., Tamura, M. and Velaphi, S. (2010) Neonatal Resuscitation Chapter Collaborators. Part 11: Neonatal Resuscitation: 2010 International Consensus on Cardiopulmonary Resuscitation and Emergency Cardiovascular Care Science with Treatment Recommendations. Resuscitation, 81, e260-e287.

https://doi.org/10.1016/j.resuscitation.2010.08.029 